\title{
Immunohistochemical Characterization of the Inflammatory Responses in Wound Healing and the Use of the Subcutaneous Polyvinyl Alcohol (PVA) Sponge Implantation Model for Evaluation of the Healing Process
}

Seham A Abd El-Aleem ${ }^{1^{*}}$, Abir Abdelhadi Muftah ${ }^{2}$ and Edward B Jude ${ }^{3}$

${ }^{1}$ Department of Histology, Minia Faculty of Medicine, Egypt

${ }^{2}$ Department of Pathology, Garyounis University, Libya

${ }^{3}$ Tameside Hospital NHS Foundation Trust and The University of Manchester, UK

*Corresponding author: Abd El-Aleem SA, Department of Histology, Minia Faculty of Medicine, Egypt, Tel: +201002997270; E-mail: Seham.abdelaleem@minia.edu.eg Received date: August 10, 2018; Accepted date: August 24, 2018; Published date: August 27, 2018

Copyright: (c) 2018 Abd El-Aleem SA, et al. This is an open-access article distributed under the terms of the Creative Commons Attribution License, which permits unrestricted use, distribution, and reproduction in any medium, provided the original author and source are credited.

\section{Abstract}

Background: Biologic and synthetic biomaterials have been used for various medical applications and research studies. Subcutaneous implantation of Polyvinyl Alcohol (PVA) sponge is a commonly used experimental model to study the underlying mechanisms of wound healing. As a research tool, PVA sponge is useful for analyzing the granulation tissue formation and tissue regeneration.

Hypothesis and Aims: PVA sponge model might show a different inflammatory response from the open incisional wound model because it reflects the host response to a foreign body. Thus, this study aims to characterize the inflammatory responses in the two models.

Materials and Methods: Adult male albino rats were used to produce the two models of wound healing. Through a midline incision, two PVA sponges were implanted subcutaneously on each side. Two incisional dermal wounds were produced on the dorsum of each rat. At the end of the experiments, the sponges and the incisional wounds were harvested at different time points for assessing the inflammatory responses. Immunohistochemical staining was used to study the cellular localization and the profile of the inflammatory markers iNOS and TGF Beta-and Western blot analysis used to study their protein levels.

Results: Immunohistochemical staining and Western blot analysis showed a distinct variability in the inflammatory responses between the two wound models. PVA sponge implantation model showed a delayed and a persistent inflammation started 3 days post-implantation and persisted as long as the sponge existed. On the other hand, the incisional wound model showed an early and a time limited response started 1 day and ended 5-7 days post-wounding. Moreover, the inflammatory mediators iNOS and TGF Beta-1 were differentially regulated in both models. While, they showed a similar profile along the time course in the PVA sponge model. They showed a differential profile in the open wound model.

Conclusion: subcutaneous PVA sponge provides an ideal reproducible model for use in inflammation research. However, it may not be a reliable model for wound healing modulation studies. It elects inflammatory response considerably different from what happens in the tissues. Furthermore, in open wound model, inflammation is differentially controlled by iNOS and TGF Beta-1. Therefore, abnormal wound healing conditions could be treated by pharmacological intervention using nitric oxide (NO) and TGF Beta-1 modulators.

Keywords: Wound healing; Polyvinyl alcohol sponge; Inflammatory mediators; Inflammation; iNOS; TGF beta

\section{Abbreviations}

PVA: Polyvinyl Alcohol; TGF Beta: Transforming Growth Factor Beta; iNOS: Inducible Nitric Oxide Synthase; NO: Nitric Oxide

\section{Introduction}

Different types of wounds in the skin or in the internal organs progress through the same events that end by healing [1]. Inflammation is the most important phase that controls the fate of healing [2]. Understanding the normal histological picture of the inflammatory phase of wound, would identify the pathophysiological factors underlying abnormal healing and would provide a line for prophylactic/therapeutic measurements. There are several models of wound, each model has advantages and disadvantages [3] but for our study it is important to use the models that can inform about the inflammatory phase. Open dermal incisional or exertional wound models have been extensively used $[3,4]$. These are accurate models of naturally occurring lesions however are associated with ongoing changes in the adjacent unwounded areas affecting the healing [4]. Subcutaneous implantation of synthetic biologically inert matrices has been used as models of wound healing and modulation studies [4-7]. The principle for using this model is that the implanted matrices provide a framework to induce a response in the tissue with formation of granulation and fibrovascular tissues [8], mimicking phases of the 
Citation: Abd El-Aleem SA, Muftah AA, Jude EB (2018) Immunohistochemical Characterization of the Inflammatory Responses in Wound Healing and the Use of the Subcutaneous Polyvinyl Alcohol (PVA) Sponge Implantation Model for Evaluation of the Healing Process. J Cytol Histol 9: 519. doi:10.4172/2157-7099.1000519

Page 2 of 13

open wound such as inflammation, angiogenesis and collagen deposition [9-17]. Thus, researchers used implantation techniques as a model of wound healing to study inflammation, angiogenesis, inflammatory mediator production and pharmacological reactivity under normal and pathological conditions [18-24]. However, it should be noted this is a model of inflammation rather than wound healing because implantation provides a chronically inflamed tissue with granulation tissue formation [18]. Biologic and synthetic biomaterials have been used for varying medical applications and research studies. As a research tool, PVA sponge is useful for analyzing the granulation tissue formation, the collagen deposition, the wound fluid composition and tissue regeneration $[25,26]$. It has also been used for investigation of stem cell survival, drug delivery and tumor angiogenesis [27,28]. Inflammation is regulated by a number of biological mediators including nitric oxide (NO), growth factors and cytokines [29-34]. Inducible nitric oxide synthase (iNOS) produces nitric oxide (NO), a major mediator of macrophage cytotoxicity under inflammatory conditions [35-37]. iNOS and TGF Beta-1 are synthesized in the wound $[35,36]$. Monitoring iNOS and TGF Beta-1 levels is commonly used as a parameter for assessing the progress of healing [38-40].

This study, characterize the PVA sponge subcutaneous implantation model by studying the cellularity, inflammatory response and inflammatory mediator regulation. Additionally, it characterizes the differences in the inflammatory responses between the implantation and the open injury models. This would provide information about the choice of model that might be used for therapeutic intervention in wound healing.

\section{Materials and Methods}

\section{Animal}

Adult male Sprague Dawley rats, 225 to $250 \mathrm{~g}$, age and weight matched, (5 per group) were housed singly for a week prior to and up till the end of the experiment. Standard rat diet and water were allowed. At The end of the experiments the animals were sacrificed by chloroform overdose. Housing and anesthesia concurred with the guidelines established by the local Institutional Animal Welfare Committee.

\section{PVA Sponge implantation model}

Sterile PVA sponges were prepared as previously described (22). Briefly, PVA sponges with dimensions 5 thick, $5 \mathrm{~mm}$ wide and $10 \mathrm{~mm}$ long were soaked overnight in $70 \% \mathrm{v} / \mathrm{v}$ ethanol and boiled in distilled water for $15 \mathrm{~min}$ before implantation. Under stringent aseptic precautions $5 \mathrm{~cm}$ long incision was made at the midline on the back of the rat. In each rat four PVA sponges were implanted into a subcutaneous pouch on both right and left sides through the incision and the skin was sutured. The animals were monitored for any sign of infection at the operative site, discomfort or distress. At the end of the experiments the PVA sponges were harvested 2, 3, 5,7,10 and 14 days post-wounding through an incision at the midline. For immunostaining, one PVA sponge from each animal was embedded in Optimal Cutting Temperature (OCT) compound and frozen for cryosectioning. The other three PVA sponges were squeezed by sterile forceps to collect the wound fluid for western blotting. From a preliminary experiment, the tissue fluid from the implanted PVA sponges was enough to run western blotting 1 day post-implantation.

\section{Wounding procedures}

In the back of each animal, two full thickness incisions one $\mathrm{cm}$ each was made at the midline under halothane anesthesia. The animals were killed by chloroform overdose at 1, 2, 3, 5, 7 and 10 days postwounding and the wounds were harvested. From each rat, the wounds were taken to include the wound area and about half $\mathrm{cm}$ from the surrounding non-wounded skin. One wound cut transversely across the midline was used for immunostaining and the other wounds used for western blotting. Normal skin from the back of non-wounded rats was used as control. Tissues for immunostaining were embedded in OCT and frozen for cryo-sectioning and wounds for western blotting were homogenized for western blot analysis.

\section{Cryo-sectioning}

Frozen OCT blocks were sectioned at seven microns thickness on poly-l-lysine coated slides. Sections were then fixed in acetone for 6 minutes, air dried and stored at $-20^{\circ} \mathrm{C}$ until used for staining. Sampling of the wounds was standardized by selecting at least three sections from identical sites within the wounds for each staining. PVA sponges were sectioned at regular distance to obtain consecutive sections $500 \mu \mathrm{m}$.

\section{Immunohistochemical staining}

Sections were rinsed in TBS for 5 minutes. Endogenous peroxidases were blocked by treatment with $0.5 \%$ hydrogen peroxide (H2O2) in methanol. Sections were incubated in the diluted primary antibody (CD68 1:500) overnight at $4^{\circ} \mathrm{C}$. The staining was completed using Novolink kits (Leica Novolink Polymer Detection System, Catalogue number: RE7150-K) and reagents were prepared and used according to the manufacturer's instructions. Briefly, sections were incubated with post-primary (30 minutes at room temperature) followed by polymer (30 minutes at room temperature). Reactions were developed with 3,3' diaminobenzidine substrate (Sigma) dissolved in distilled water for the appropriate period. Sections were then counterstained with haematoxylin and dehydrated prior to mounting with DPX and coverslipped for microscopic examination. Positive signals appear as brown staining on the sections with the counterstaining in blue. Specimens were viewed using a Leica DRRB microscope and images were captured using a Spot RT Slider digital camera (Image Solutions) using Spot RT software run on a PC. Macrophage Marker: CD68 mouse monoclonal antibody (Dako, M0814).

\section{Nuclear staining for the PVA sponge sections}

Sections of the PVA sponges were processed for staining the nuclei. Hoechst No. 33258 (2883 Sigma-Aldrich) was used. It is a fluorescent DNA-selective dyes for staining the nuclei. Sections were washed 5 minutes in TBS at room temperature. Then sections were incubated in Hoechst No. 33258 1: 1000 for 15 minutes at room temperature. Nuclei were labelled blue. Sectioned were viewed by Leica DMRB microscope operating in fluorescence mode with appropriate filter sets and images were captured.

\section{Single immunofluorescence staining}

Sections were defrosted and rinsed with PBS. The primary antibody was diluted to required concentration (TGF Beta-1, 1:300 and iNOS, 1:500) and added to the sections for overnight incubation at $4^{\circ} \mathrm{C}$. Sections were then incubated with the appropriate secondary antibody 
Citation: Abd El-Aleem SA, Muftah AA, Jude EB (2018) Immunohistochemical Characterization of the Inflammatory Responses in Wound Healing and the Use of the Subcutaneous Polyvinyl Alcohol (PVA) Sponge Implantation Model for Evaluation of the Healing Process. J Cytol Histol 9: 519. doi:10.4172/2157-7099.1000519

Page 3 of 13

(TRITC a conjugated goat anti-mouse for TGB beta-1 and FITC conjugated goat anti-rabbit for iNOS) for one hour at room temperature. Sections were then washed with PBS mounted with Gelvatol, cover slipped and stored in lightproof boxes at $-20^{\circ} \mathrm{C}$ to dry before being viewed for analysis. Sectioned were viewed by Leica DMRB microscope operating in fluorescence mode with appropriate filter sets for analysis and image capturing. The antibodies used were: Mouse monoclonal anti-TGF beta 1 primary antibody (ab64715) Rabbit polyclonal anti-iNOS primary antibody (1:1000 Transduction laboratories). Goat Anti-Mouse TRITC conjugated secondary antibody (ab6786). Goat Anti-Rabbit FITC conjugated secondary (ab97050).

\section{Double immunofluorescence staining}

Sections were prepared and incubated with antibody to TGF Beta-1 antibody $(1: 300)$ overnight at $4^{\circ} \mathrm{C}$. Then, washed and incubated for a further thirty minutes with TRITC conjugated goat anti-mouse secondary antibody diluted 1:200 in TBS. Sections were then incubated with antibody to iNOS (1:500) for one hour at room temperature. Then, washed and incubated with FITC conjugated goat anti-rabbit secondary antibody $1: 100$ in TBS for thirty minutes at room temperature. Sections were mounted in Gelvatol, cover slipped and stored in lightproof boxes at $-20^{\circ} \mathrm{C}$. Sectioned were viewed by Leica DMRB microscope operating in fluorescence mode with appropriate filter sets for image capturing and analysis.

\section{Homogenization and Western blot analysis}

Tissues were homogenized in a mixture of protease inhibitors (10 $\mathrm{mg} / \mathrm{ml}$ leupeptin, $10 \mathrm{mg} / \mathrm{ml}$ peptastatin $\mathrm{A}$, and $100 \mathrm{mg} / \mathrm{ml}$ phenylmethylsulphonyl fuoride) in $50 \mathrm{mM}$ Tris $\pm \mathrm{HCl}, \mathrm{pH}$ 7.5. After spinning for $15 \mathrm{~min}$ at $2000 \mathrm{~g}$, the supernatants were used for western blot analysis. The protein concentration in the supernatant and in the wound fluid obtained from the PVA sponges was measured by the Bradford assay [41] using bovine serum albumin as a standard. The protein concentrations in all the samples were equalized. The samples were mixed with gel loading buffer $(50 \mathrm{mM}$ Tris $\mathrm{HCl}, 10 \% \mathrm{SDS}$, $10 \%$ glycerol, $10 \% 2$ mercaptoethanol, $2 \mathrm{mg} / \mathrm{ml}$ bromophenol blue) in a ratio of $1: 1$ and then boiled for $8 \mathrm{~min} .30 \mu \mathrm{l}$ of each sample was loaded in each well on a $10 \%$ SDSpolyacrylamide minigel (Bio-Rad) using the Laemmli buffer system. The proteins were transferred to $0.45 \mu \mathrm{m}$ nitrocellulose membranes using a transblotting apparatus (Bio-Rad). The transfer was performed overnight using transfer buffer $(25 \%$ methanol, $1.5 \%$ glycine and $0.3 \%$ Tris-base). Non-specific IgG binding was blocked by incubation with $5 \%$ dried milk protein for three hours. Then the membrane was incubated overnight at $4^{\circ} \mathrm{C}$ with diluted primary antibody (iNOS 1:1000 and TGF Beta-1 1:500). The bands were detected using an amplified alkaline phosphatase kit (Sigma, Poole, UK) and developed with 5-bromo-4-chloro-3indolylphosphate/nitroblue tetrazolium (Sigma, Poole, UK) as a chromogen. Broad range pre-stained rainbow markers (Bio-Rad Laboratories, Hemel Hempstead, UK) were used for molecular weight determinations.

\section{Image Analysis and counting of immunoreactive cells at the wounds}

Sections were immunostained with the markers (iNOS and TGF Beta-1) and image analysis was carried out to establish the number of positively stained cells in each animal. For the PVA sponge model, cells were counted in 20 fields per section using objective X20. For the open incisional wound model sections were analyzed at $20 \mathrm{X}$ magnification.
Six areas of each wound were captured as shown (Figure 1); two areas from the left wound margin $(1,2)$, two areas from the right wound margin $(3,4)$, one area from the top of the central wound bed (5) and one area from the bottom of the central wound bed (6).

\section{Statistical analyses}

Statistical analysis is performed using IBM SPSS statistical package. Results were expressed as the mean \pm SEM. Expression data were compared using Mann-Whitney $U$ test comparing the expression levels in each experimental group to the control unwounded group in the open injury model or to the two days group in the PVA sponge subcutaneous implantation model, with $\mathrm{P}<0.05$ being considered as statistically significant.

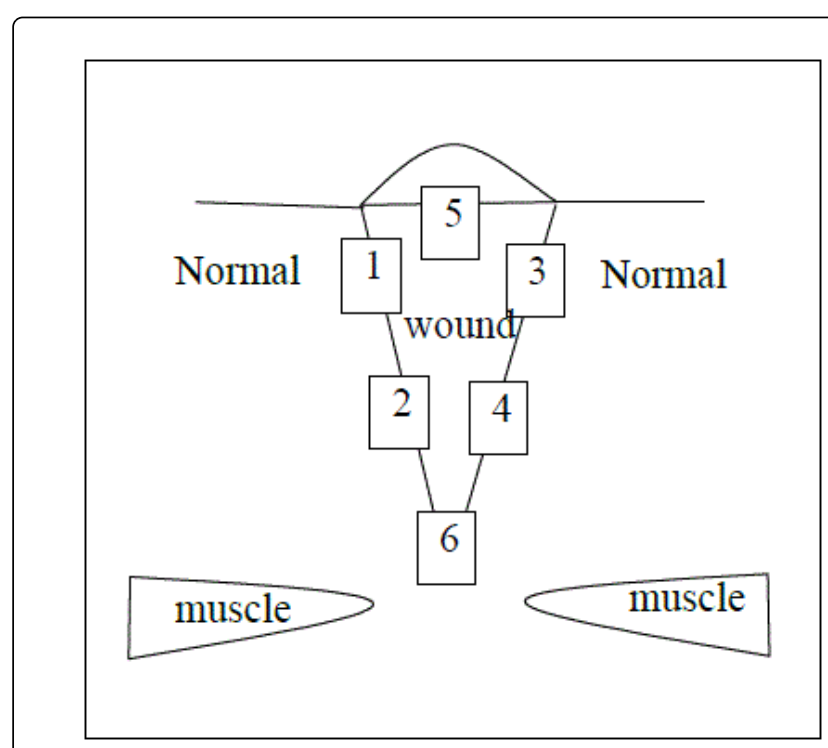

Figure 1: Wound model.

\section{Results}

Subcutaneous implantation of PVA sponge induced inflammatory response with granulation and fibrovascular tissue formation. The reaction to the PVA sponge implantation was weakly detectable at early time points 1-3 days post-implantation (Figure $2 \mathrm{~A}$ and $2 \mathrm{~B}$ ). Macroscopic examination of the implanted PVA sponges showed wound fluid and exudate filling the PVA sponge pores (Figure 2B and 2C). 14 days post implantation, the PVA sponges showed shrinkage and irregularity in the shape due to the fibrovascular changes in the granulation tissues within the PVA sponge and filling the PVA sponge pores with thick exudate (Figure 2D). Macroscopic and microscopic examination of the PVA sponge showed that the most prominent inflammatory response was seen 5-7 days post-implantation (Figures $2 \mathrm{C}, 3 \mathrm{C}$ and $3 \mathrm{D}$ ). This was indicated by the increase in the cellularity (Figure 3C) and vascularity (Figure 3D) of the granulation tissue. The granulation tissues were composed of a dense inflammatory infiltrate, with macrophages, spindle-shaped like fibroblasts and proliferating endothelial cells forming vessels. The staining pattern in the cells was characterized by the presence of cellular aggregates and clusters (Figure 3). 
Citation: Abd El-Aleem SA, Muftah AA, Jude EB (2018) Immunohistochemical Characterization of the Inflammatory Responses in Wound Healing and the Use of the Subcutaneous Polyvinyl Alcohol (PVA) Sponge Implantation Model for Evaluation of the Healing Process. J Cytol Histol 9: 519. doi:10.4172/2157-7099.1000519

Page 4 of 13

\section{Cellularity, macrophage infiltration and inflammatory markers in the PVA sponge}

Histological examination of sections of the PVA sponges showed infiltration by inflammatory cells and granulation tissue formation (Figure 3). The cellularity was studied by a nuclear marker that stains all nuclei. The nuclear marker gives an idea about the cellular infiltration but does not differentiate types of cells. Thus, the results were further supported by using inflammatory markers such as macrophage marker CD68 (Figure 4A and 4B), iNOS (Figures 5A and 6) and TGF Beta-1 (Figures 5B and 6).
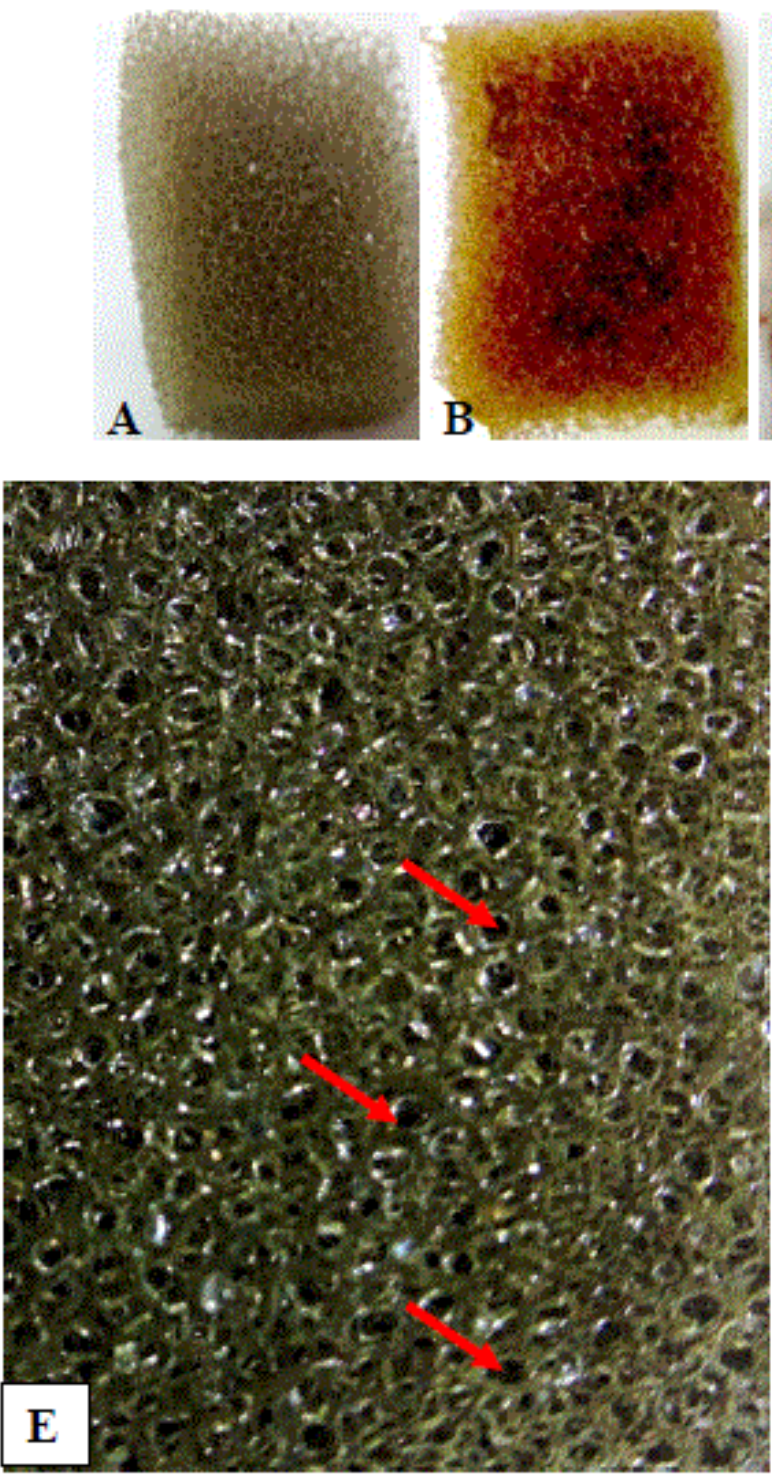
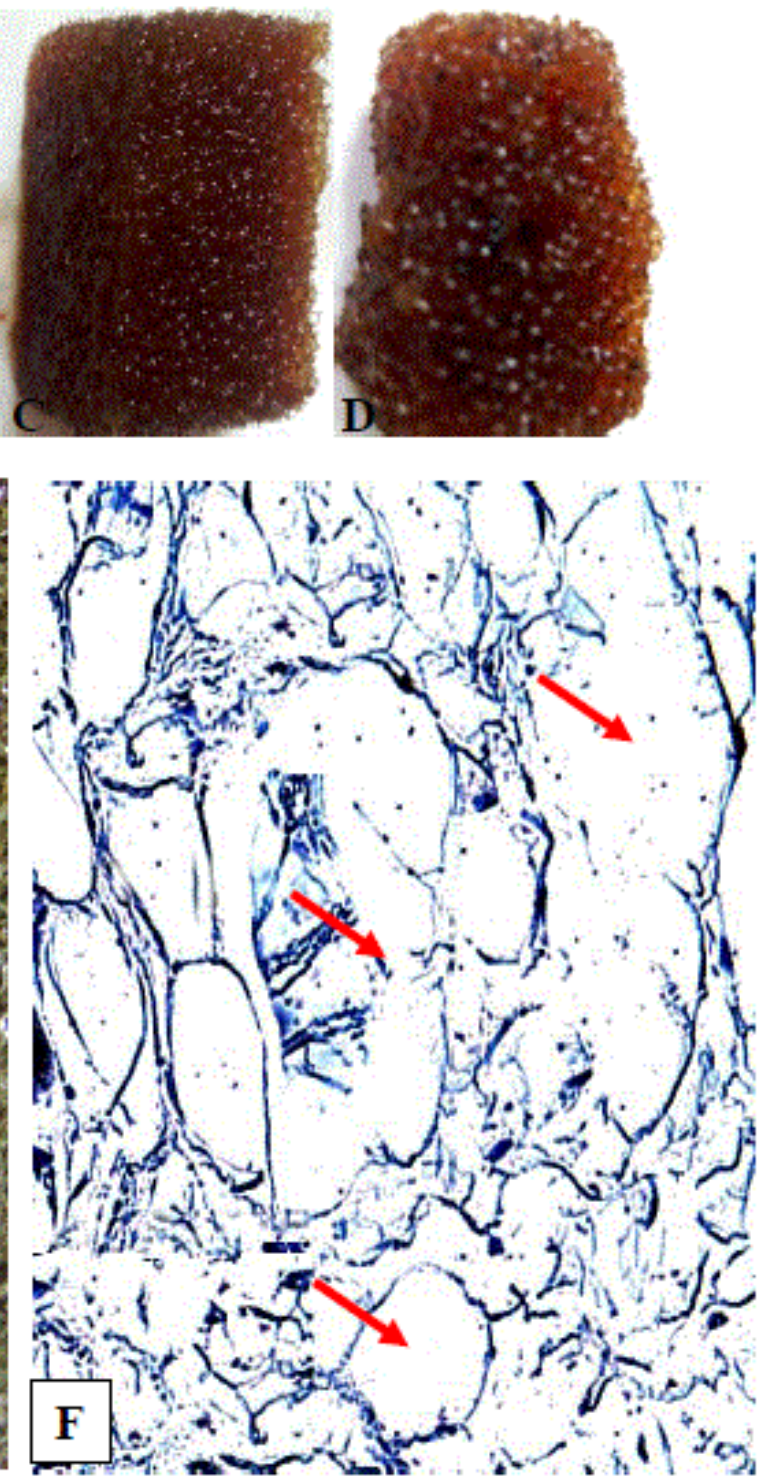

Figure 2: A representative photograph showing the PVA sponge macroscopically (A-D) and microscopically (E). A) Prior to the implantation. B) 3 Days post-implantation showing the sponge pores full of wound fluid and blood. C) 7 Days post-implantation showing the sponge pores full of wound exudate. D) 14 Days post-implantation showing the sponge pores full of wound exudate, with sponge shrinkage. E) Zooming into the sponge prior to the implantation showing the pores macroscopically. F) Toluidine blue staining showing the sponge microscopically (arrows). Sponge is formed of network of matrix and pores (arrows). Toluidine blue, $\mathrm{D}=\mathrm{X} 4$. 
Citation: Abd El-Aleem SA, Muftah AA, Jude EB (2018) Immunohistochemical Characterization of the Inflammatory Responses in Wound Healing and the Use of the Subcutaneous Polyvinyl Alcohol (PVA) Sponge Implantation Model for Evaluation of the Healing Process. J Cytol Histol 9: 519. doi:10.4172/2157-7099.1000519
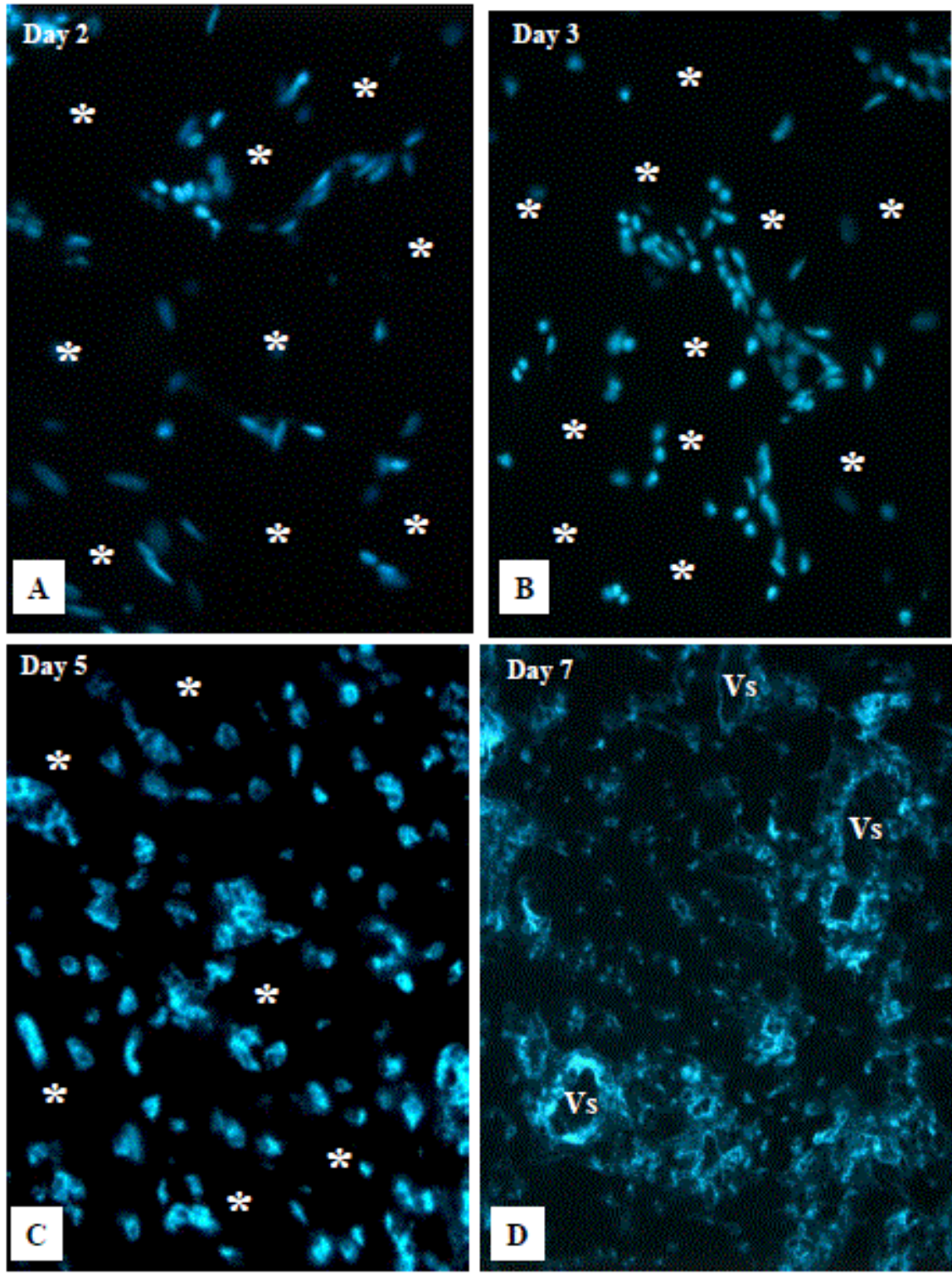

Figure 3: A representative photomicrograph showing Hoechst nuclear staining for demonstration of the cellularity of a histological section of a PVA sponge post-implantation. A) 2 Days showing few cells along the sponge matrix network delineating the sponge pores (stars). B) 3 Days showing a slight increase in the cellularity of the granulation within the sponge. C) 5 Days showing marked increase in the cellularity of the granulation within the sponge. D) 7 Days showing filling the sponge pores by fibrovascular tissues composed of vessels (Vs) and cells. Hoechst nuclear stain, $\mathrm{A}, \mathrm{B}=\mathrm{X} 10, \mathrm{C}=\mathrm{X} 20, \mathrm{D}=\mathrm{X} 4$. 
Citation: Abd El-Aleem SA, Muftah AA, Jude EB (2018) Immunohistochemical Characterization of the Inflammatory Responses in Wound Healing and the Use of the Subcutaneous Polyvinyl Alcohol (PVA) Sponge Implantation Model for Evaluation of the Healing Process. J Cytol Histol 9: 519. doi:10.4172/2157-7099.1000519

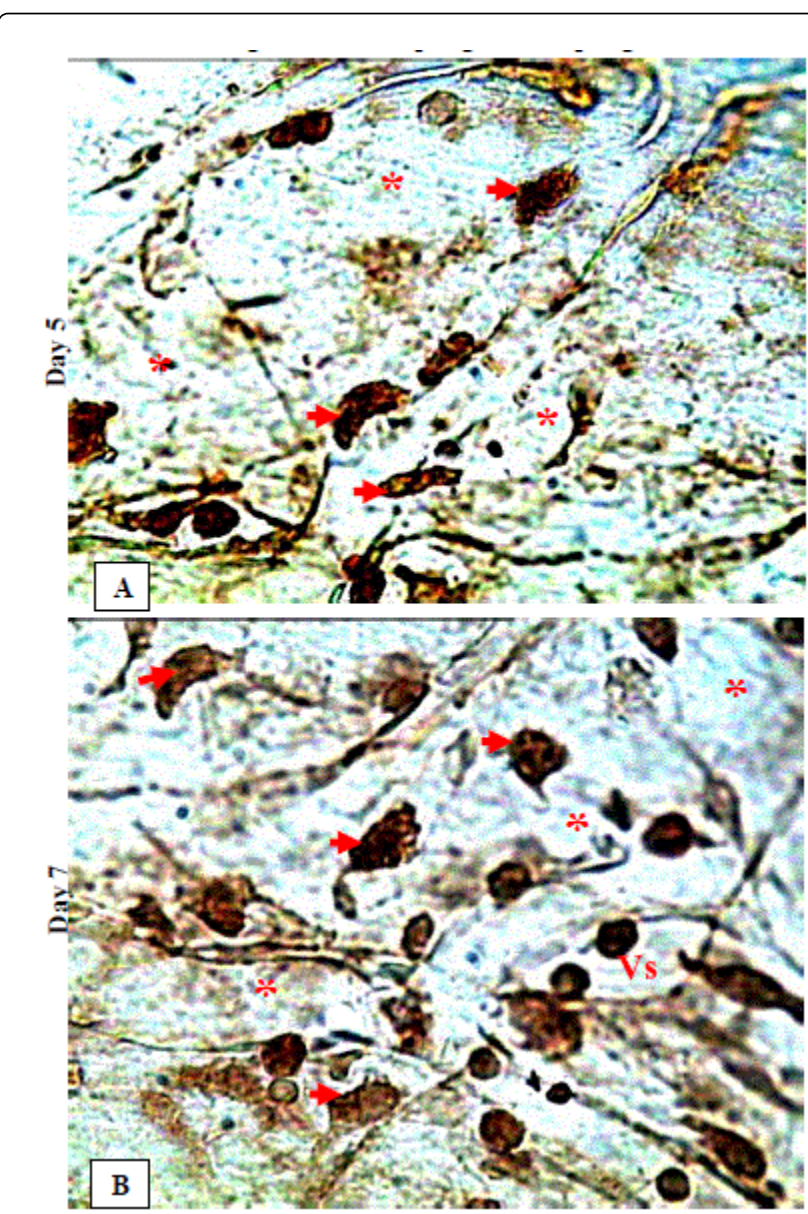

Figure 4: A representative photomicrograph showing CD68 immunostaining for detection of macrophages infiltration of the subcutaneously implanted PVA sponge. Macrophages (arrows) are seen along the sponge matrix networks in between the sponge pores (stars) 5 (A) and 7 (B) days post-implantation. Notice 7 Days postimplantation, there is apparent increase in the number of the macrophages and narrowing of the sponge pores (stars) indicating shrinkage of the sponge due to increase fibrovascular component of the granulation tissues. Immunohistochemistry, A, B=X40.

The cellularity of the formed granulation tissues increases along the time course, with only few cells seen 2 and 3 days post-implantation (Figure $3 \mathrm{~A}$ and $3 \mathrm{~B}$ ). Increase in the cellularity was most prominent 5 days post-wounding (Figure $3 \mathrm{C}$ ). The granulation tissues showed fibrovascular changes seen mainly 7 days post-implantation (Figure 3D). The infiltrating inflammatory cells within the granulation tissues were seen along the PVA sponge matrices network in between the sponge pores (Figure 3A-3C).

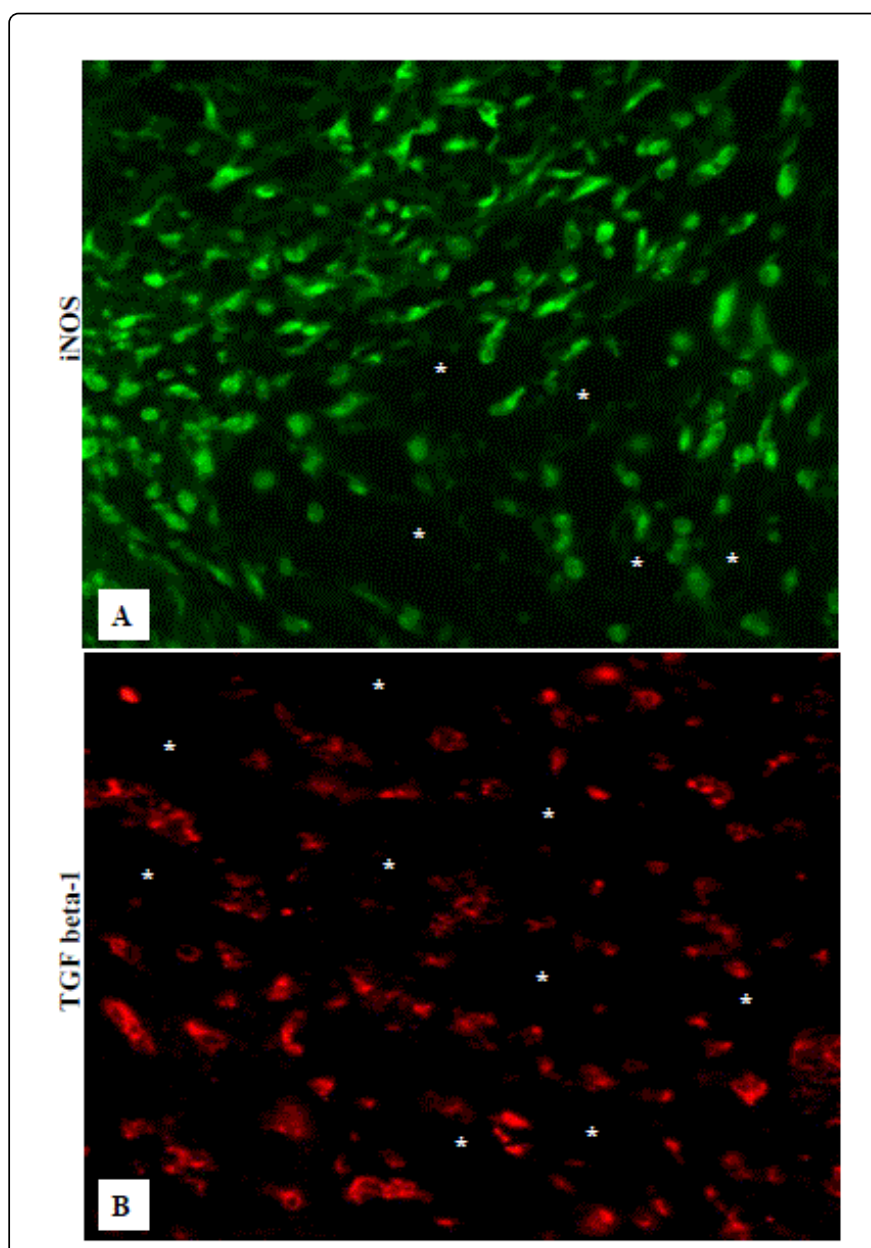

Figure 5: A representative photomicrograph showing the immunoreactivity of iNOS (A) and TGF Beta-1 (B) of the granulation tissues 5 days post-implantation. There is marked increase in the cellularity of the granulation tissue. A large number of cells expressing iNOS (A) and TGF Beta-1 (B) are seen rowing along the sponge matrix lining the pores (stars). Immunofluorescences, A, B=X20.

Macrophages were detected by immunohistochemical staining as a marker for inflammatory response in the implanted PVA sponge. There was macrophage invasion into the granulation tissue within the PVA sponge 5 (Figure 4A) and 7 (Figure 4B) days post-implantation. Macrophages were seen along the sponge matrix network in between the pores (Figure 4). 7 Day post-wounding there was apparent increase in macrophages infiltration of the sponge (Figure 4B) and narrowing of the sponge pores indicating shrinkage of the sponge due to increase fibrovascular component of the granulation tissues. 
Citation: Abd El-Aleem SA, Muftah AA, Jude EB (2018) Immunohistochemical Characterization of the Inflammatory Responses in Wound Healing and the Use of the Subcutaneous Polyvinyl Alcohol (PVA) Sponge Implantation Model for Evaluation of the Healing Process. J Cytol Histol 9: 519. doi:10.4172/2157-7099.1000519

Page 7 of 13

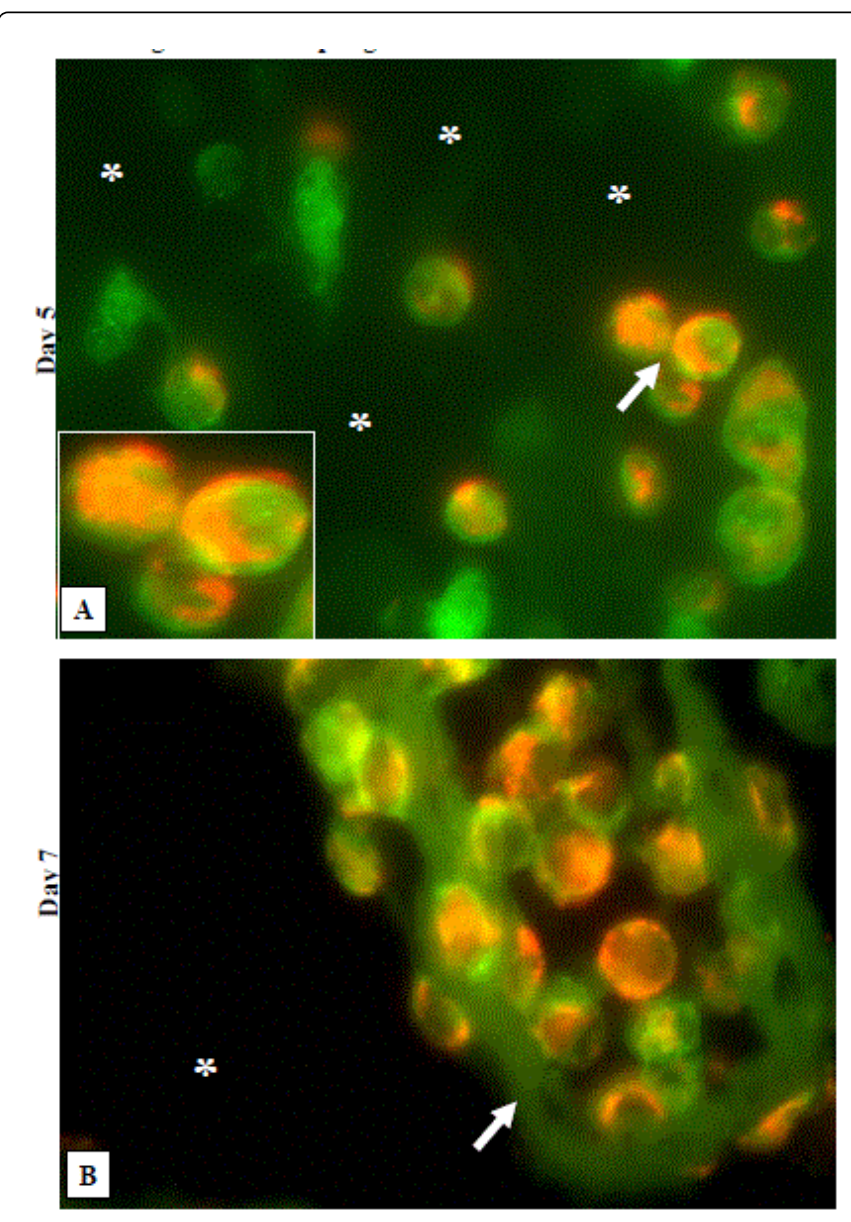

Figure 6: A representative photomicrograph showing double immunofluorescence for detection of iNOS (green) and TGF Beta-1 (Red) colocalization (yellow/orange) in the granulation tissues 5 and 7 days post-implantation. A) 5 Days, there is colocalization of iNOS and TGF Beta-1 in the inflammatory cells. Cell are seen rowing along the sponge matrix lining the sponge pores (stars). The inset shows the subcellular colocalization of both markers. B) 7 Days, there is predominance of fibrinous tissue which form network. There is cellular clustering and trapping in the fibrous network (arrow), most of cells express both markers. Double Immunofluorescence, $\mathrm{A}, \mathrm{D}=\mathrm{X} 100$.

iNOS and TGF Beta-1 immunoreactivities were detected using immunofluorescence staining as markers for the inflammatory response in the implanted PVA sponge. There was expression of iNOS (Figure 5A) and TGF Beta-1 (Figure 5B) in the infiltrating inflammatory cells within the granulation tissues post-implantation. Cells were rowing along the sponge matrices in between the sponge pores (Figure 5).
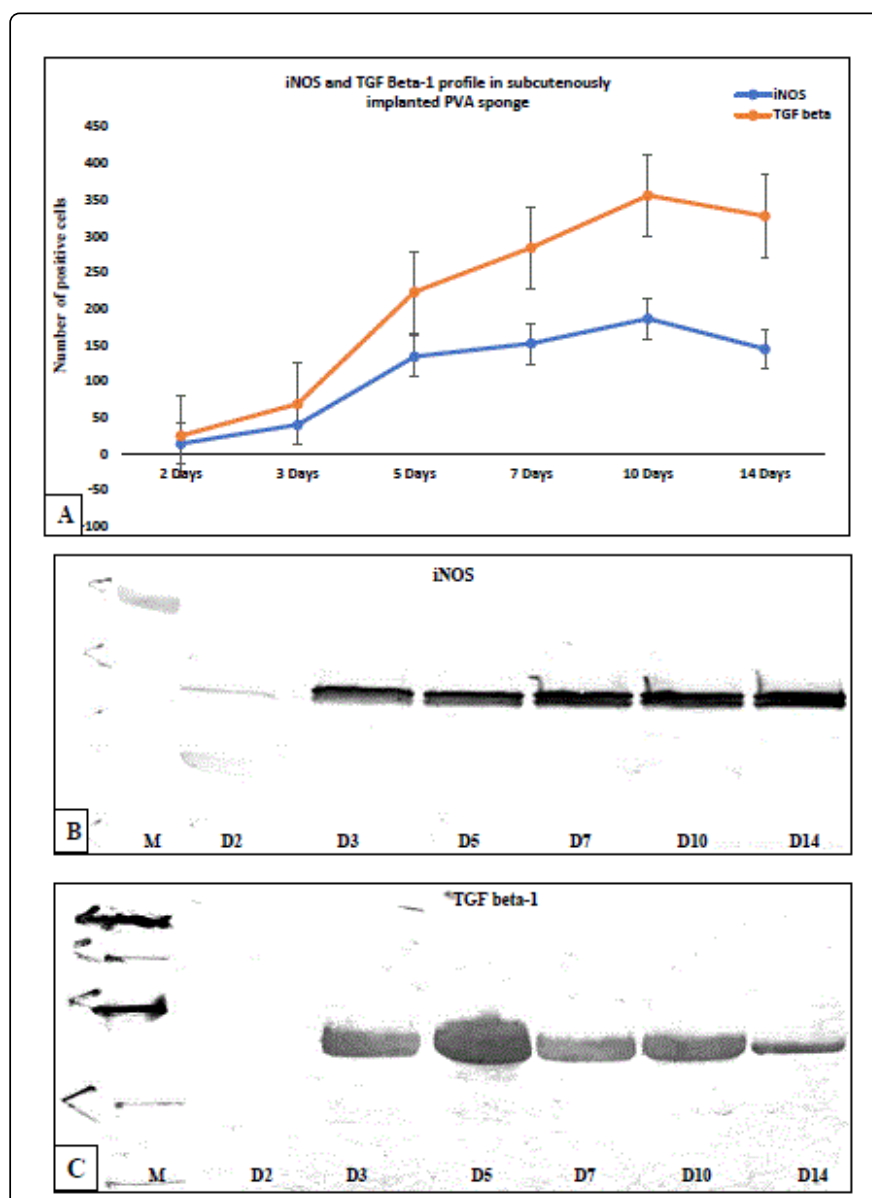

Figure 7: Morphometric analysis of iNOS and TGF Beta-1 immunoreactivity and protein levels in the PVA sponge at different time post-implantation. A) A graph showing the number of wound iNOS/TGF Beta-1 immunoreactive cells in the granulation tissues along the time course. Both markers show a gradual increase starting 3 days and persisting up to 10 days post-implantation. B, C) Western blot analysis showing the protein levels of iNOS and TGF Beta-1 in the wound fluid. The profile of protein levels in the wound fluid is similar to the profile of immunoreactivity in the granulation tissues.

Double immunofluorescence showed co-expression of iNOS and TGF Beta-1 in cells infiltrating the granulation tissues 5 (Figure 6A) and 7 (Figure 6B) days post-implantation. Interestingly 7 days postimplantation there was formation of fibrous tissues within the granulation tissue with trapping of clustering cells within the fibrous network (Figure 6B). 
Citation: Abd El-Aleem SA, Muftah AA, Jude EB (2018) Immunohistochemical Characterization of the Inflammatory Responses in Wound Healing and the Use of the Subcutaneous Polyvinyl Alcohol (PVA) Sponge Implantation Model for Evaluation of the Healing Process. J Cytol Histol 9: 519. doi:10.4172/2157-7099.1000519

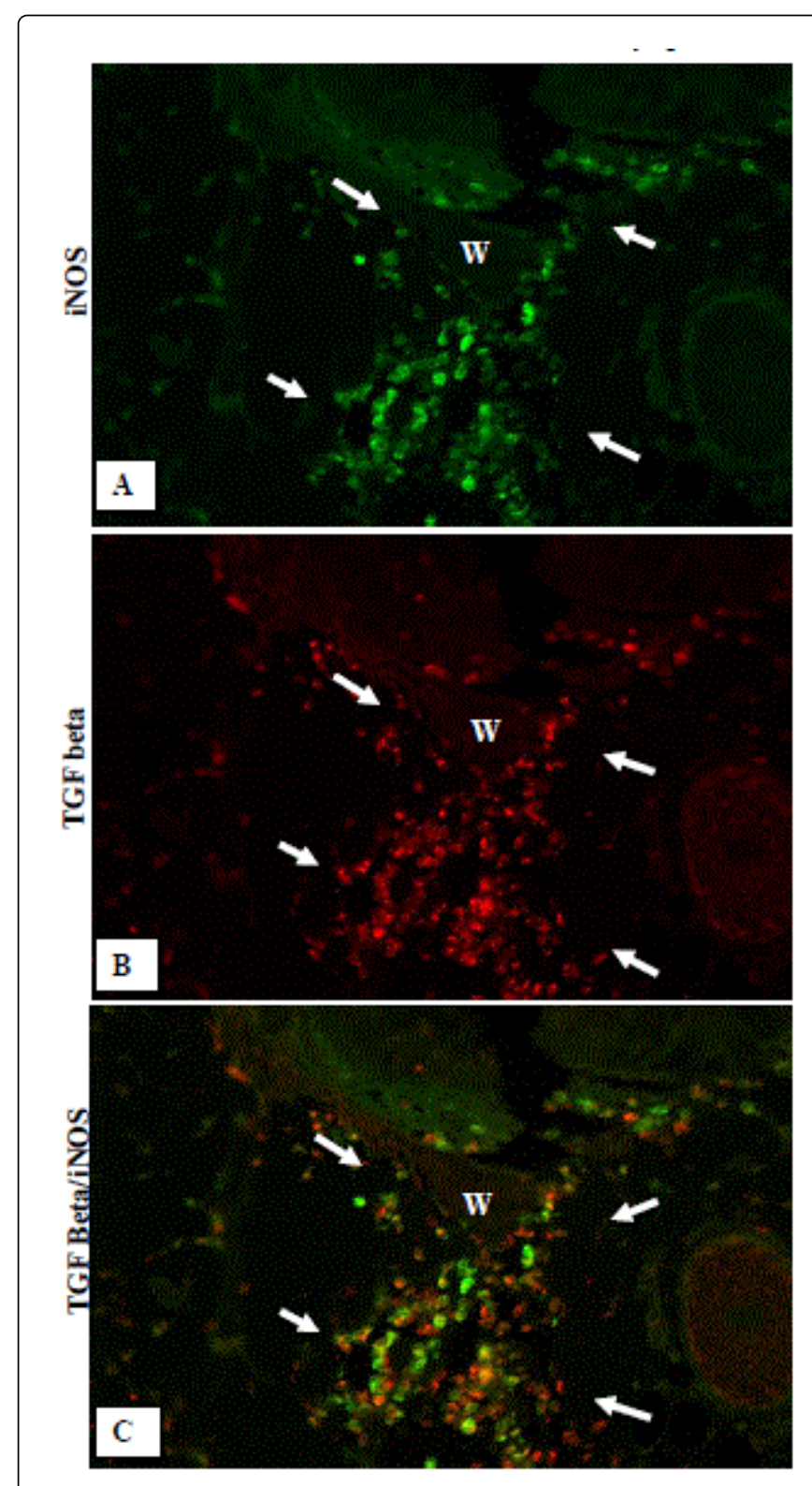

Figure 8: Double immunofluorescence showing iNOS (Green) and TGF Beta-1 (red) colocalization (yellow/orange) in the wound gap 2 days post-wounding: A) iNOS is expressed in a large number of inflammatory cells. B) TGF Beta-1 is seen in a few inflammatory cells. C) Merging images $A$ and $B$ shows that iNOS immunoreactivity is the predominant staining. Double immunofluorescence, $\mathrm{A}-\mathrm{C}=\mathrm{X} 20$.

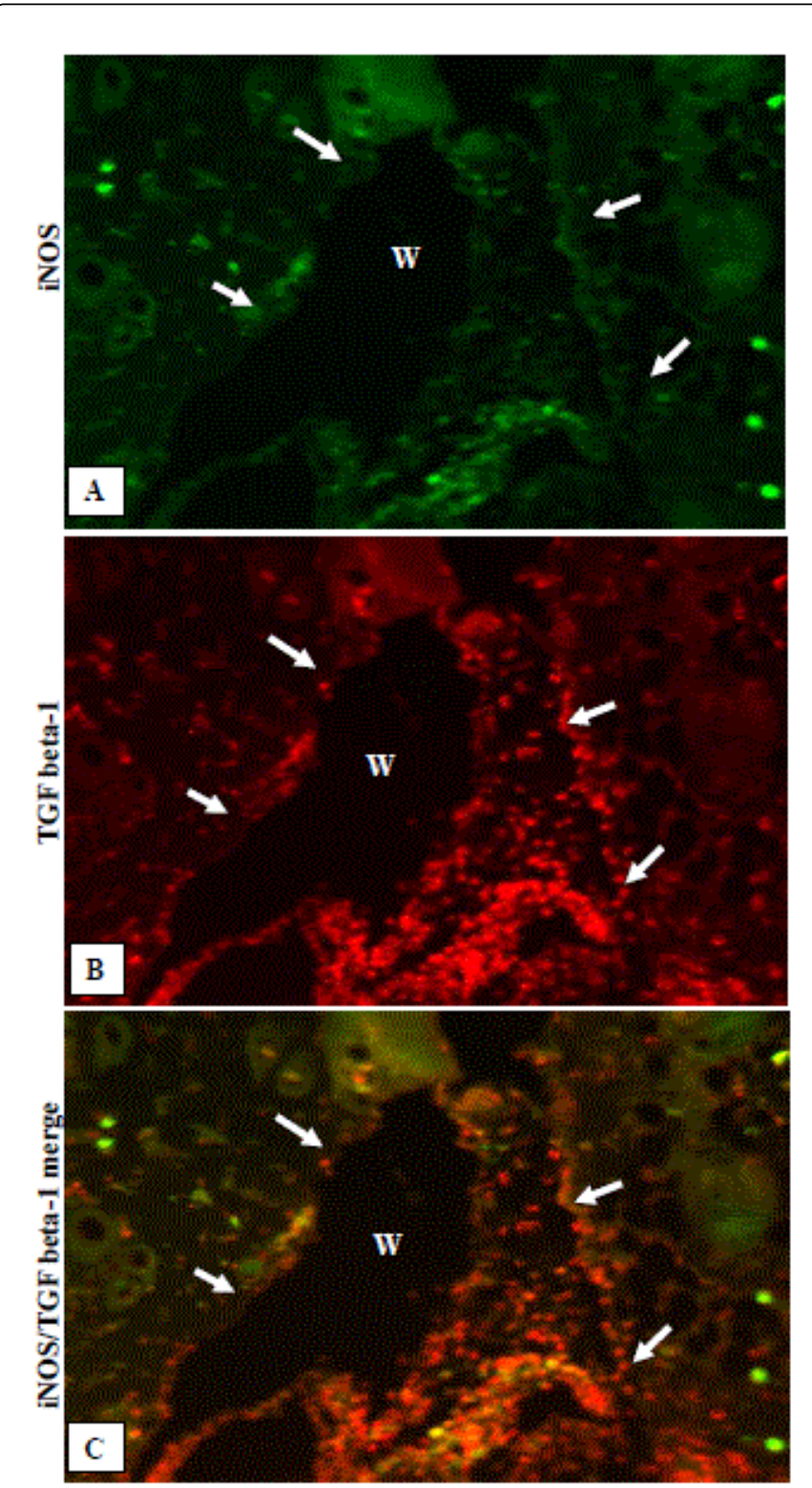

Figure 9: Double immunofluorescence showing iNOS (Green) and TGF Beta-1 (red) colocalization (yellow/orange) in the wound 3 days post-wounding. A) TGF Beta-1 is expressed in a large number of inflammatory cells. B) iNOS is expressed in a few inflammatory cells. C) Merging images $\mathrm{A}$ and $\mathrm{B}$ shows that TGF Beta-1 immunoreactivity is the predominant staining. Double immunofluorescence, $\mathrm{A}-\mathrm{C}=\mathrm{X} 10$. 
Citation: Abd El-Aleem SA, Muftah AA, Jude EB (2018) Immunohistochemical Characterization of the Inflammatory Responses in Wound Healing and the Use of the Subcutaneous Polyvinyl Alcohol (PVA) Sponge Implantation Model for Evaluation of the Healing Process. J Cytol Histol 9: 519. doi:10.4172/2157-7099.1000519

Page 9 of 13

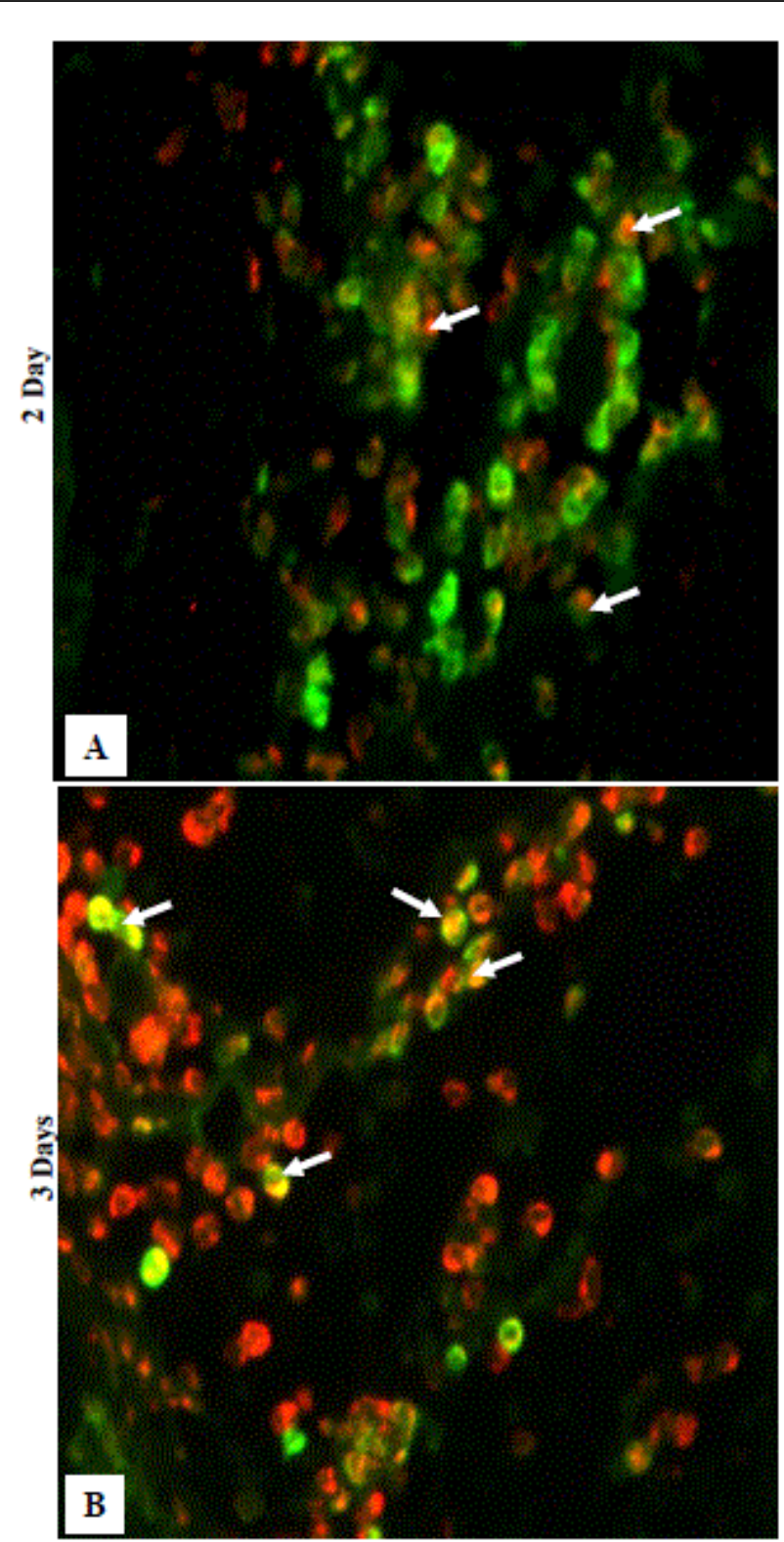

Figure 10: Higher magnification showing double immunofluorescence staining for iNOS and TGF Beta-1, 2 and 3 days post-wounding. A) 2 Days post-wounding, there is a predominance of iNOS immunoreactivity (green). B) 3 Days postwounding, there is a predominance of TGF Beta-1 immunoreactivity (red). There is co-expression of iNOS and TGF Beta-1 in few cells (arrows). Double immunofluorescence, A, $\mathrm{B}=\mathrm{X} 40$.

\section{Morphometric analysis of the histological sections of PVA sponge}

There was a gradual increase in the iNOS and TGF Beta-1 immunoreactivity over a time course (Table 1). Starting three days post-implantation and continued to increase up to 14 days postimplantation (Figure 7A). Interestingly, this was confirmed further by western blot analysis. Western blot showed expression of iNOS (Figure 7B) and TGF Beta-1 (Figure 7C) proteins along the time course starting from day 3 and persist till day 14 post-implantation. Therefore, the changes in the number of the inflammatory cells expressing iNOS/TGF Beta-1 assessed by immunofluorescence was paralleled by a similar change in the protein levels assessed by western blot. This adds further confirmatory evidence about the regulation of both markers in the PVA sponge.

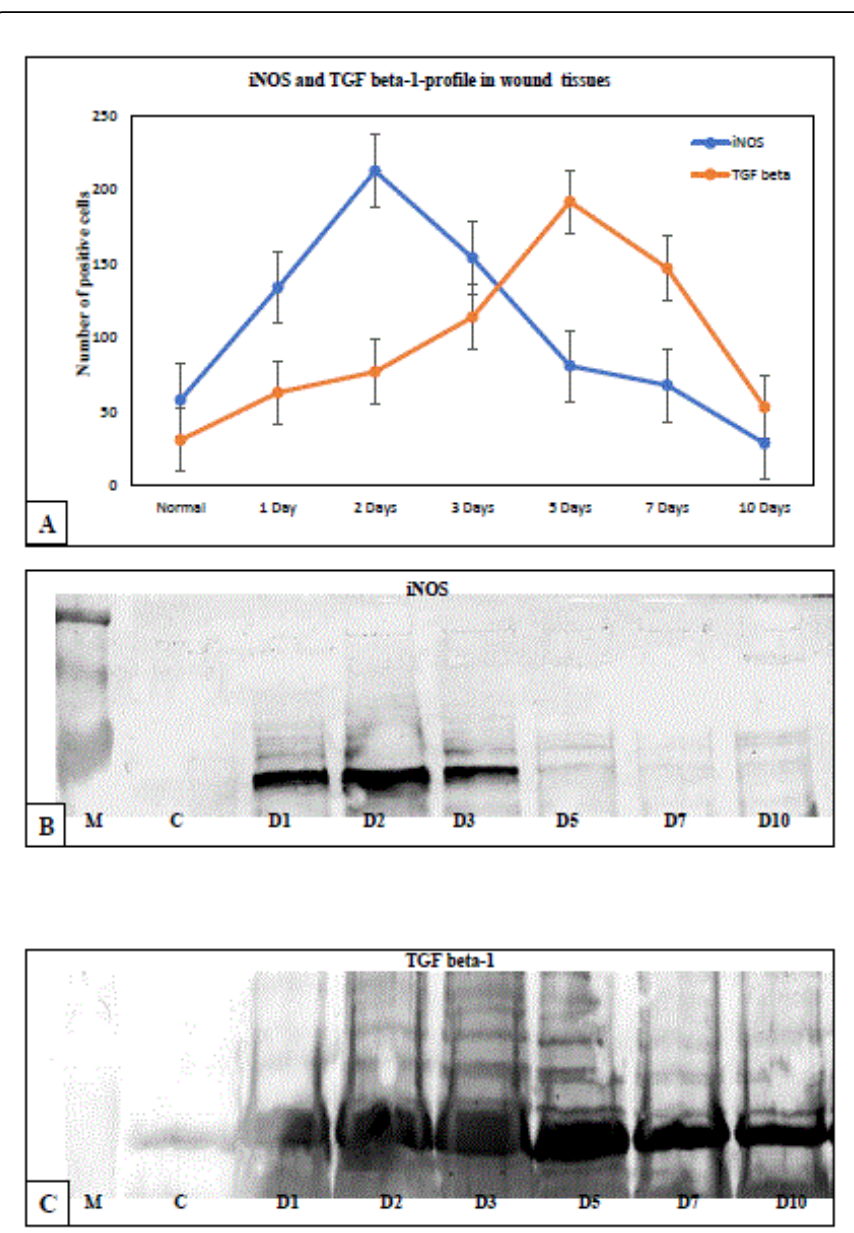

Figure 11: Morphometric analysis of iNOS and TGF Beta-1 immunoreactivity and protein levels at different time points postwounding. A) A graph showing the number of iNOS/TGF Beta-1 immunoreactive cells in the wound tissue along the time course. iNOS and TGF Beta- 1 show a distinct pattern of expression. While iNOS shows upregulation 1-3 days post-wounding. TGF bta-1 shows upregulation 1-7 days post-wounding. B, C) Western blot analysis showing wound iNOS (B) and TGF Beta-1 (B) protein levels at different time points. While iNOS was induced for short period 1-3 days post-wounding. TGF Beta-1 shows upregulation for a longer period 1-10 days post. The changes in the wound immunoreactivities for both markers are paralleled by a similar pattern in the protein levels assessed by western blotting. 
Citation: Abd El-Aleem SA, Muftah AA, Jude EB (2018) Immunohistochemical Characterization of the Inflammatory Responses in Wound Healing and the Use of the Subcutaneous Polyvinyl Alcohol (PVA) Sponge Implantation Model for Evaluation of the Healing Process. J Cytol Histol 9: 519. doi:10.4172/2157-7099.1000519

Page 10 of 13

\section{iNOS and TGF Beta-1 expression in the open incisional wounds at different time points}

Immunofluorescent staining showed iNOS and TGF Beta-1 immunoreactivity at the wounds (Figures $8-10$ ). This was mostly seen at early time points; 1 day (Figure 8 ) and 3 days (Figure 9) postwounding. The immunoreactivities were morphometrically analysed by counting the number of cells expressing iNOS or TGF Beta-1 at different time point. This show a significant (Table 2) increase in iNOS and TGF Beta-1 at early time pointes by comparison to the controls unwounded skin (Figure 11A). Interestingly iNOS and TGF Beta-1 showed differential timing of expression. While iNOS upregulation was during the early phase of healing 1-3 days post-wounding, TGF Beta-1 TGF Beta-1 continued upregulated up for longer time to and including 7 days post-wounding. Table 2 summarise iNOS and TGF Beta-1 levels in wound tissues at different time points. Interestingly, western blot analysis of the protein levels of the wound iNOS and TGF Beta-1 showed a similar pattern to the immunoreactivity (Figure 11B and $11 \mathrm{C}$ ) adding further support to the immunostaining finings.

\begin{tabular}{|l|l|l|l|l|}
\hline Groups & iNOS & P Value & TGF Beta-1 & P Value \\
\hline 2 Days Post-implantation & $14 \pm 2$ & & $11 \pm 2$ & \\
\hline 3 Days Post-implantation & $40 \pm 7^{*}$ & $\mathrm{P}<0.04$ & $28 \pm 5^{*}$ & $\mathrm{P}<0.01$ \\
\hline 5 Days Post-implantation & $134 \pm 22^{* *}$ & $\mathrm{P}<0.001$ & $70.2 \pm 6^{*}$ & $\mathrm{P}<0.02$ \\
\hline 7 Days Post-implantation & $152 \pm 26^{* *}$ & $\mathrm{P}<0.001$ & $132 \pm 15^{* * *}$ & $\mathrm{P}<0.0001$ \\
\hline 10 Days Post-implantation & $186 \pm 14^{* *}$ & $\mathrm{P}<0.001$ & $194 \pm 28^{* * *}$ & $\mathrm{P}<0.0001$ \\
\hline 14 Days Post-implantation & $144 \pm 26^{* *}$ & $\mathrm{P}<0.001$ & $\mathrm{P}<0.001$ \\
\hline $\begin{array}{l}\text { Readings represent the average number of positive cells at each time point. } \\
\text { Results are expressed as the mean } \pm \text { SEM. }{ }^{*} \mathrm{P} \text { value }<0.05,{ }^{* *} \mathrm{P}<0.001,{ }^{* * *} \mathrm{P}<0.0001 .\end{array}$ & & \\
\hline
\end{tabular}

Table 1: Changes in the levels of iNOS and TGF Beta-1 immunoreactivities in the granulation tissue induced by subcutaneous PVA sponge implantation at different time points.

\begin{tabular}{|c|c|c|c|c|}
\hline Groups & iNOS & P Value & TGF Beta-1 & P Value \\
\hline Control & $58 \pm 12$ & & $31 \pm 4$ & \\
\hline 1 Day post-wounding & $181 \pm 70$ * & $P<0.010$ & $63 \pm 9^{*}$ & $P<0.036$ \\
\hline 2 Days post-wounding & $175 \pm 25^{\star \star *}$ & $P<0.0001$ & $77 \pm 6^{* *}$ & $P<0.004$ \\
\hline 3 Day post-wounding & $132 \pm 15^{\star *}$ & $P<0.002$ & $114 \pm 10^{\star * *}$ & $P<0.0001$ \\
\hline 5 Days post-wounding & $81.3 \pm 9$ & $P<0.411$ & $192 \pm 16^{\star \star *}$ & $P<0.0001$ \\
\hline 7 Days post-wounding & $68 \pm 9$ & $P<0.719$ & $147 \pm 13^{\star * *}$ & $P<0.0001$ \\
\hline 10 Days post-wounding & $29 \pm 5$ & $P<0.295$ & $53 \pm 9$ & $P<0.140$ \\
\hline
\end{tabular}

Table 2: Changes in the levels of wound iNOS and TGF Beta-1 immunoreactivities in wounds at different time points.

\section{Discussion}

In this study we have shown that PVA sponge model exhibits a distinct pattern of inflammatory response that differs from the incisional dermal wound. Furthermore, the inflammatory mediators iNOS and TGF Beta-1 showed a differential expression in the two models. While in the PVA sponge, iNOS and TGF beta were produced as long as the PVA sponge exists, in the dermal incisional wound they have time limited expression. Our data was in agreement with previous studies [42-45]. Therefore, in the PVA sponge implantation model, the inflammation remains for as long as the stimulus persists, probably as reaction to a foreign body. Thus, this model can be used as an inflammatory model rather than a wound healing model which is a multiphase with time limit $[1,2]$. Moreover, there are local and paracrine production of mediators such as iNOS and TGF Beta-1 that could promote organogenesis and remodeling [45]. These, properties in addition to the chemical properties of the PVA sponge like its nontoxicity and biocompatibility endorse its use in the modern technologies of medicine and pharmacy [25-30,46-48].

This study showed that PVA sponge promoted cellular infiltration, in agreement with [47]. PVA elicit a foreign body response with biomolecules and protein adhesion to the surface with subsequent inflammatory response $[5,45,46]$. The secreted chemotactic inflammatory mediators recruit mast cells to the sponge with subsequent production of vasoactive histamine and heparin which cause vasodilation and inflammatory cell infiltration into the sponge [46,48-50]. Macrophages phagocytose small particles, bacteria and 
Citation: Abd El-Aleem SA, Muftah AA, Jude EB (2018) Immunohistochemical Characterization of the Inflammatory Responses in Wound Healing and the Use of the Subcutaneous Polyvinyl Alcohol (PVA) Sponge Implantation Model for Evaluation of the Healing Process. J Cytol Histol 9: 519. doi:10.4172/2157-7099.1000519

Page 11 of 13

dead cells. However, they are unable to digest the implants [5]. This series of events could account for the persistent inflammation with continuous production of iNOS and TGF Beta-1.

The early upregulation of iNOS and TGF Beta-1 in both inflammatory models and colocalization of both markers provide evidence that they were expressed as a part of the integrated response to inflammatory stimuli. Factors available in the wound area such as lipopolysaccharides (LPS) and cytokines may upregulate both iNOS and TGF Beta-1 simultaneously [33]. The timing of iNOS and TGF Beta-1 upregulation was coincident with that of the infiltration of the wound by inflammatory cells, angiogenesis and induction of some cytokines which are usually upregulated during the inflammatory phase [51]. Following injury, there is inflammation and and bacterial invasion [3]. The release of bacterial lipopolysaccharide in induces iNOS synthesis in the neutrophils and macrophages to produce NO [2,33]. NO has antimicrobial and antiproliferative activities [52]. Furthermore, NO maintains blood flow to the injured tissues facilitating nutrition and cell infiltration $[8,52]$. Therefore, the upregulated iNOS increases NO production to overcome the cytotoxic environment through antimicrobial, vasodilatation and antiplatelet aggregation activities [8,53]. TGF Beta-1 is a fibrogenic cytokine $[53,54]$, its upregulation postinjury in both models, could favour growth and repair as it is essential for cell proliferation and differentiation, protein and collagen synthesis [54,55] essential requirements for completion of the healing. Indeed, NO upregulation to overcome the cytotoxic environment and TGF Beta-1 upregulation to promote postinjury repair are a requirement for both models of injury. However, iNOS and TGF Beta-1 showed a different pattern of expression in the open wound model which is worth discussing in further details.

Interestingly, we have shown a distinct pattern of iNOS and TGF beta- 1 regulation in the open incisional wound model, while iNOS expression predominated the wound environment 1-3 days postwounding. TGF Beta-1 predominated 1-7 days post-wounding. This could be explained by a number of factors. Firstly, the producing cells, iNOS is produced by neutrophils $[56,57]$ the first defence cells migrate into the wound and predominate at early phase after injury [56-58]. Moreover, neutrophils produce cytokines that induce iNOS [57-59]. On the other hand, TGF Beta-1 is produced by macrophages, fibroblasts and mast cells which infiltrate wounds at a later phase of inflammation [60,61]. Secondarily, the wound biochemical environment in the late stages of inflammation reduces iNOS. In this concept, TGF Beta production in the wound [54,55] inhibits iNOS [62] and induces mediators such as arginase [63] and prostaglandins E2 [64,65] which inhibit iNOS [63]. Thirdly, autoregulation, iNOS produces $\mathrm{NO}$ which combines with hydroxyl free radicals forming peroxynitrite $[66,67]$ which along with superoxide and other toxic free radicals, causes cell lysis [52]. This lysis may lead to the release of arginase within the extracellular space. Arginase inhibits iNOS through competition for $\mathrm{L}$ arginine substrate $[52,53]$. In summary, the differential expression of iNOS and TGF Beta-1 in the open injury model is regulated by the wound cellularity, growth factors and the wound biochemistry.

The pattern of expression of iNOS and TGF Beta-1 in the open wound could be a physiological requirement for healing. Early postinjury the wound environment is cytotoxic with bacterial invasion [3]. The release of bacterial lipopolysaccharide in the wound induces iNOS synthesis in the neutrophils and macrophages to produce NO $[2,33]$. NO has antimicrobial and antiproliferative activities [52,66].
Furthermore, NO maintains blood flow to the wound facilitating nutrition and cell infiltration [8,52]. Therefore, the predominance of iNOS in the early stage increase wound NO production to overcome the cytotoxic environment through antimicrobial, vasodilatation and antiplatelet aggregation activities $[8,66,67]$. Downregulation of $\mathrm{NO}$ at a late stage could protect the tissue from the damaging effects of $\mathrm{NO}$ which could interfere with healing by inhibiting cellular proliferation and protein and collagen synthesis $[8,68,69]$. Furthermore, the low level of NO could neutralise the oxygen free radicals released by infiltrated leukocytes, thus protecting cells from damage by oxygen and hydroxyl radicals [70]. Alternatively, at later time points, the increase in TGF Beta-1 could favour growth and repair as it is essential for cell proliferation and differentiation $[54,55]$ protein and collagen synthesis $[54,55]$ essential requirements for completion of the healing. In this context, it should be noted that TGF $\beta$ which is known to be a potent fibrogenic cytokine that enhances wound healing has been reported to inhibit NO production by macrophages [62].

\section{Conclusion}

This study explores key finding for inflammation and wound healing research. Firstly, PVA sponge model explores the pathogenesis of inflammation and identifies targets for drug discovery to modulate inflammation. Secondarily, it reveals differences in inflammatory response in the PVA sponge model and open incisional wound model. Thus, PVA sponge implantation would be more appropriate as an inflammation model rather than a wound healing model. Thirdly, in open wound model, inflammation is differentially controlled by iNOS and TGF Beta-1. It is likely that, interference with these physiological responses to injury could alter the healing process and results in abnormal healing. Low NO production results in delay resolution of inflammation as in diabetes. Uncontrolled continuous NO production results in chronic inflammation as in chronic ulcers. Excessive uncontrolled production of TGF beta in the inflammatory phase of wounds results in excessive fibrosis as in keloid. Therefore, abnormal wound healing conditions could be treated by pharmacological intervention using NO and TGF Beta-1 modulators.

\section{References}

1. Martin P (1997) Wound healing-aiming for perfect skin regeneration. Science 276: 75-81.

2. Sanderson KV (1967) Book Review: Advances in Biology of Skin. Proceedings of the Royal Society of Medicine 60: 718-719.

3. Willoughby D (1970) Some views on the pathogenesis of inflammation. Saint Bartholomew's Hospital Medical Coll London (England) Dept of Pathology.

4. DiPietro LA, Burns AL (2003) Wound healing: methods and protocols. Springer.

5. Ibrahim M, Bond J, Medina MA, Chen L, Quiles C, et al. (2017) Characterization of the foreign body response to common surgical biomaterials in a murine model. European journal of plastic surgery 40 : 383-392.

6. Campos P (2006) Cellular proliferation, differentiation and apoptosis in polyether-polyurethane sponge implant model in mice. Histology and histopathology 21: 1263-1270.

7. Viljanto J, Penttinen R, Raekallio J (1981) Fibronectin in early phases of wound healing in children. Acta chirurgica Scandinavica 147: 7-13.

8. Machado R, Santos R, Andrade S (2001) Mechanisms of angiotensin-(17)-induced inhibition of angiogenesis. American Journal of PhysiologyRegulatory, Integrative and Comparative Physiology 280: R994-R1000. 
Citation: Abd El-Aleem SA, Muftah AA, Jude EB (2018) Immunohistochemical Characterization of the Inflammatory Responses in Wound Healing and the Use of the Subcutaneous Polyvinyl Alcohol (PVA) Sponge Implantation Model for Evaluation of the Healing Process. J Cytol Histol 9: 519. doi:10.4172/2157-7099.1000519

Page 12 of 13

9. Barcelos L (2004) Production and in vivo effects of chemokines CXCL1-3/KC and CCL2/JE in a model of inflammatory angiogenesis in mice. Inflammation Research 53: 576-584.

10. 10. Belo A (2004) Inhibition of inflammatory angiogenesis by distant subcutaneous tumor in mice. Life sciences 74: 2827-2837.

11. O'brien FJ (2011) Biomaterials and scaffolds for tissue engineering. Materials today 14: 88-95.

12. Jiang X, Xiang N, Zhang H, Sun Y, Lin Z, et al. (2018) Preparation and characterization of poly (vinyl alcohol)/sodium alginate hydrogel with high toughness and electric conductivity. Carbohydrate polymers 186 377-383.

13. Brown DL, Kao WW, Greenhalgh DG (1997) Apoptosis down-regulates inflammation under the advancing epithelial wound edge: delayed patterns in diabetes and improvement with topical growth factors. Surgery 121: 372-380.

14. Singer AJ, Clark RA (1999) Cutaneous wound healing. New England journal of medicine 341: 738-746.

15. Machado RD, Santos RA, Andrade SP (1999) Opposing actions of angiotensins on angiogenesis. Life sciences 66: 67-76.

16. Ferreira MA (2004) Sponge-induced angiogenesis and inflammation in PAF receptor-deficient mice (PAFR-KO). British journal of pharmacology 141: 1185-1192.

17. Gabbiani G (2003) The myofibroblast in wound healing and fibrocontractive diseases. The Journal of Pathology: A Journal of the Pathological Society of Great Britain and Ireland 200: 500-503.

18. Davidson J (1998) Animal models for wound repair. Archives of dermatological research 290: S1-S11.

19. Yannas IV, Tzeranis DS, So PT (2017) Regeneration of injured skin and peripheral nerves requires control of wound contraction, not scar formation. Wound Repair and Regeneration 25: 177-191.

20. Walsh D (1996) Innervation and neurokinin receptors during angiogenesis in the rat sponge granuloma. The Histochemical journal 28: 759-769.

21. Ford HR (1989) Characterization of wound cytokines in the sponge matrix model. Archives of Surgery 124: 1422-1428.

22. Efron DT, Barbul A (2003) Subcutaneous sponge models. Wound Healing, Springer, pp: 83-93.

23. Deskins DL, Ardestani S, Young PP (2012) The polyvinyl alcohol sponge model implantation. Journal of visualized experiments: JoVE.

24. Rompen E (2006) The effect of material characteristics, of surface topography and of implant components and connections on soft tissue integration: a literature review. Clinical oral implants research 17: 55-67.

25. McNally AK (2008) Vitronectin is a critical protein adhesion substrate for IL-4-induced foreign body giant cell formation. Journal of Biomedical Materials Research Part A 86: 535-543.

26. Xie Z (2013) Dual growth factor releasing multi-functional nanofibers for wound healing. Acta biomaterialia 9: 9351-9359.

27. Alaish SM, Bettinger DA, Olutoye OO, Gould LJ, Yager DR, et al. (1995) Comparison of the polyvinyl alcohol sponge and expanded polytetrafluoroethylene subcutaneous implants as models to evaluate wound healing potential in human beings. Wound Repair and Regeneration 3: 292-298.

28. Sprugel K (1987) Effects of growth factors in vivo. I. Cell ingrowth into porous subcutaneous chambers. The American journal of pathology 129 601-613.

29. Garland CJ, McPherson GA (1992) Evidence that nitric oxide does not mediate the hyperpolarization and relaxation to acetylcholine in the rat small mesenteric artery. British journal of pharmacology 105: 429-435.

30. Braiman-Wiksman L (2007) Novel insights into wound healing sequence of events. Toxicologic pathology 35: 767-779.

31. Luo JD, Chen AF (2005) Nitric oxide: a newly discovered function on wound healing. Acta Pharmacologica Sinica 26: 259

32. Chang C-I, Liao JC, Kuo L (1998) Arginase modulates nitric oxide production in activated macrophages. American Journal of PhysiologyHeart and Circulatory Physiology 274: H342-H348.
33. Willoughby DA, Tomlinson A (1999) Inducible enzymes in the inflammatory response. Springer Science and Business Media.

34. Albina JE (1990) Temporal expression of different pathways of 1-arginine metabolism in healing wounds. The Journal of Immunology 144: 3877-3880.

35. Ischiropoulos H (1992) Peroxynitrite-mediated tyrosine nitration catalyzed by superoxide dismutase. Archives of biochemistry and biophysics 298: 431-437.

36. Nathan C, Xie Q-W (1994) Nitric oxide synthases: roles, tolls, and controls. Cell 78: 915-918.

37. Schäffer MR (1997) Nitric oxide metabolism in wounds. Journal of Surgical Research 71: 25-31.

38. Lee TY (1999) Expression of transforming growth factor beta 1, 2, and 3 proteins in keloids. Annals of plastic surgery 43: 179-184.

39. Miyzono K, Heldin C (1992) Structure, function and possible clinical application of TGF-beta 1. Dermatology 19: 644-647.

40. Haynes JH (1994) Platelet-derived growth factor induces fetal wound fibrosis. Journal of pediatric surgery 29: 1405-1408.

41. Kruger NJ (2009) The Bradford method for protein quantitation. In: Walker JM, (Ed.) The Protein Protocols Handbook. Humana Press: Totowa, NJ, pp: 17-24.

42. Sonoki T (1997) Coinduction of nitric-oxide synthase and arginase $I$ in cultured rat peritoneal macrophages and rat tissues in vivo by lipopolysaccharide. Journal of Biological Chemistry 272: 3689-3693.

43. Lee RH (2001) Nitric oxide in the healing wound: a time-course study. Journal of Surgical Research 101: 104-108.

44. Serhan CN, Savill J (2005) Resolution of inflammation: the beginning programs the end. Nature immunology 6: 1191-1197.

45. Chung HJ, Park TG (2007) Surface engineered and drug releasing prefabricated scaffolds for tissue engineering. Advanced drug delivery reviews 59: 249-262.

46. Aziz M, Jacob A, Yang W-L, Matsuda A, Wang P (2013) Current trends in inflammatory and immunomodulatory mediators in sepsis. Journal of leukocyte biology 93: 329-342.

47. Akasaka Y (2004) Basic fibroblast growth factor promotes apoptosis and suppresses granulation tissue formation in acute incisional wounds. The Journal of Pathology 203: 710-720.

48. Karimi A, Navidbakhsh M, Faghihi S (2014) Retracted: Fabrication and mechanical characterization of a polyvinyl alcohol sponge for tissue engineering applications. Perfusion 29: 231-237.

49. Olbrich KC (2005) Halofuginone inhibits collagen deposition in fibrous capsules around implants. Annals of plastic surgery 54: 293-296.

50. Morehead J, Holt G (1994) Soft-tissue response to synthetic biomaterials. Otolaryngologic clinics of North America 27: 195-201.

51. Shearer JD (1997) Differential regulation of macrophage arginine metabolism: a proposed role in wound healing. American Journal of Physiology-Endocrinology And Metabolism 272: E181-E190.

52. Nussler AK, Billiar TR (1993) Inflammation, immunoregulation, and inducible nitric oxide synthase. Journal of leukocyte biology 54: 171-178.

53. Witte MB, Barbul A (2002) Role of nitric oxide in wound repair. The American Journal of Surgery 183: 406-412.

54. Shah M, Foreman DM, Ferguson M (1995) Neutralisation of TGF-beta 1 and TGF-beta 2 or exogenous addition of TGF-beta 3 to cutaneous rat wounds reduces scarring. Journal of cell science 108: 985-1002.

55. Shah M (1999) Role of elevated plasma transforming growth factor-betal levels in wound healing. Am J Pathol 154: 1115-1124.

56. Frank S (2002) Nitric oxide drives skin repair: novel functions of an established mediator. Kidney international 61: 882-888.

57. McCall TB, Boughton-Smith NK, Palmer RM, Whittle BJ, Moncada S (1989) Synthesis of nitric oxide from L-arginine by neutrophils. Release and interaction with superoxide anion. Biochemical Journal 261: 293-296.

58. Frank S, Madlener M, Werner S (1996) Transforming growth factors 1, 2, and 3 and their receptors are differentially regulated during normal and impaired wound healing. Journal of Biological Chemistry 271: 10188-10193. 
Citation: Abd El-Aleem SA, Muftah AA, Jude EB (2018) Immunohistochemical Characterization of the Inflammatory Responses in Wound Healing and the Use of the Subcutaneous Polyvinyl Alcohol (PVA) Sponge Implantation Model for Evaluation of the Healing Process. J Cytol Histol 9: 519. doi:10.4172/2157-7099.1000519

Page 13 of 13

59. Cassatella MA (1995) Interleukin-12 production by human polymorphonuclear leukocytes. European journal of immunology 25: 1-5.

60. Jude E (2002) Transforming growth factor-beta 1, 2, 3 and receptor type I and II in diabetic foot ulcers. Diabetic Medicine 19: 440-447.

61. El-Aleem SA, Abdelwahab S, Osman N (2017) Co-upregulation of transforming growth factor beta-1 and nitric oxide synthase in keloid by comparison to normal human skin-a possible role for $\operatorname{tgf} \beta 1$ and nos in pathogenesis of keloid. J Cytol Histol 8: 474.

62. Vodovotz Y (1999) Regulation of transforming growth factor $\beta 1$ by nitric oxide. Cancer research 59: 2142-2149.

63. Boutard V (1995) Transforming growth factor-beta stimulates arginase activity in macrophages. Implications for the regulation of macrophage cytotoxicity. The Journal of Immunology, 1995. 155(4): p. 2077-2084.

64. Corraliza IM (1995) Arginase induction by suppressors of nitric oxide synthesis (IL-4, IL-10 and PGE2) in murine bone-marrow-derived macrophages. Biochemical and biophysical research communications 206: 667-673.
65. Minghetti L (1998) Opposite regulation of prostaglandin E2 synthesis by transforming growth factor- $\beta 1$ and interleukin 10 in activated microglial cultures. Journal of neuroimmunology 82: 31-39.

66. Candy G, Gould A (2008) Arginine metabolism and wound healing: basic science review. Wound Healing Southern Africa 1: 48-50.

67. Beckman JS (1990) Apparent hydroxyl radical production by peroxynitrite: implications for endothelial injury from nitric oxide and superoxide. Proc Natl Acad Sci, USA 87: 1620-1624.

68. Kolpakov V, Gordon D, Kulik TJ (1995) Nitric oxide-generating compounds inhibit total protein and collagen synthesis in cultured vascular smooth muscle muscle cells. Circ Res 76: 305-309.

69. Cao M, Westerhausen-Larson A, Niyibizi C, Kavalkovich K, Georgescu HI, et al. (1997) Nitric oxide inhibits the synthesis of type-II collagen without altering Col2A1 mRNA abundance: prolyl hydroxylase as a possible target. Biochemical Journal 324: 305-310.

70. Rosen GM (1999) Free radicals: biology and detection by spinn trapping. Oxford University Press. 